SESSION 3213

\title{
Enhancing Underrepresented Student Opportunities Through Faculty Mentoring and Peer Interactions
}

\author{
Antonio A. Garcia, Gary D. Keller, Albert McHenry \\ Arizona State University \\ Fred Begay \\ Los Alamos National Laboratory
}

During the past seven years, an alliance of colleges and universities within Arizona, Colorado, New Mexico, Nevada, Utah, and Western Texas along with professional organizations, government laboratories, educational organizations, and corporations has been committed to one of the most challenging goals in higher education: increasing the number of African American, American Indian, and Hispanic bachelor degrees in science, mathematics, engineering, and technology. This alliance, known as the Western Alliance to Expand Student Opportunities (WAESO), has relied heavily on engaging students in academic and research activities outside the classroom involving science and engineering faculty and student peers in order to improve retention and increase graduation rates of underrepresented students.

Over the past six years we have had 4,251 student participations within our alliance activities which include: (1) peer study groups; (2) summer bridge programs; (3) faculty-directed undergraduate students research; and (4) graduate preparation, mentorships, and research conference participations. In order to provide such a large number of student participations, our alliance calls upon over 500 resource individuals at 75 campuses and organizations where approximately $85 \%$ are scientists, engineers, and other faculty, and $15 \%$ are administrators. This paper will present our strategies for: (1) engaging science and engineering faculty and students in these activities which depends upon inter-institutional cooperation; (2) documentation of student information and student outcomes; and (3) institutionalization of these activities through the use of the Internet and through faculty development.

\section{Background}

During 1991-1996 our Phase I alliance, sponsored in part by the National Science Foundation through the Alliances for Minority Participation (AMP) program, exceeded our stated goal by more than doubling the annual rate of underrepresented minority SMET (science, mathematics, engineering, and technology) baccalaureate production. In Phase II, begun in 1997, our alliance has set the goal of again doubling the annual rate of underrepresented SMET baccalaureate production from a baseline of 702 to 1,404 by the year 2001 After the first year of Phase II for the Western Alliance to Expand Student Opportunities, we exceeded our first year goal of 
increasing the number of baccalaureate degrees in SMET awarded to underrepresented minorities within our region yearly from our baseline value of 702 presented in our grant proposal to 774 in the academic year 1997. We have been tracking our progress to forward this goal by determining the rate of SMET B.S. degrees awarded to African Americans, American Indians, and Hispanics within our region (Table 1). Our overall five year goal is to double the number of underrepresented SMET baccalaureates to 1,404 in the year 2001 by gradually raising the yearly rate of increase. Our target for the first year was to raise our baseline value of 702 of SMET B.S. degrees awarded annually to African Americans, American Indians, and Hispanics to 741 at the end of year 1. We more than doubled this projected increase.

Comparing baccalaureate degrees earned in our alliance with the most recent national data available $^{1}$, we find that our alliance is responsible for $6 \%$ of the degrees awarded nationally to Hispanics and $14 \%$ of the degrees awarded nationally to American Indians in the fields of engineering, physical sciences, mathematical sciences, computer science, biological science, and agricultural sciences.

Based on the most recent national data, the annual rate of increase in the fields of engineering, physical sciences, mathematical sciences, computer science, biological science, and agricultural sciences for African Americans, American Indians, and Hispanics has been between 4.3\% - 8.7\% for the past five years that data is available. Our alliance once again continues to exceed the national rate of increase by having a $10 \%$ increase at the end of the first year of Phase II.

Table 1. Comparison of WAESO Baccalaureate Production for African Americans, American Indians, and Hispanics Before and After The First Year of Phase II

$\begin{array}{lccc}\text { Discipline } & \text { Baseline } & \mathbf{1 9 9 7} & \begin{array}{c}\text { \% Increase } \\ \mathbf{9 6 - 9 7}\end{array} \\ \text { Chemistry } & 35 & 41 & 17 \% \\ \text { Physics/Astronomy } & 12 & 5 & (58) \% \\ \text { Mathematics } & 47 & 28 & (40) \% \\ \text { Computer \& Information Science } & 84 & 71 & (15) \% \\ \text { GeoSciences } & 12 & 17 & 42 \% \\ \text { Engineering \& Applied Sciences } & 311 & 305 & (2) \% \\ \text { Biological/Life Sciences } & 131 & 203 & 55 \% \\ \text { Agricultural Sciences } & 42 & 47 & 12 \% \\ \text { All Other SEM Disciplines } & 30 & 57 & 90 \% \\ & & & \\ \text { Total: } & \mathbf{7 0 2} & \mathbf{7 7 4} & \mathbf{1 0 \%}\end{array}$

\section{Alliance Activities}

Intensive student activities are conducted throughout our region involving a large number of students and faculty. Last year we had 493 student participations within our activities which include:

- $\quad$ peer study groups (local and over the Internet);

- summer bridge programs; 
- faculty-directed undergraduate students research; and

- graduate preparation, mentorships, and research conference participations.

We have served 467 students in our Phase II activities, thus on average, about 5\% of our students participate in two activities. Most of the data is given in the form of student participation which accurately reflects the number of student engaged in a specific activity. This distribution shows that we have a concerted, focused effort which reaches a significant number of undergraduate SMET minority students within our region.

In our alliance each specific activity is developed through a peer review process similar to the peer review system at NSF. Committees made up of faculty throughout our alliance review each request for a specific activity submitted by a faculty mentor. This mechanism has made our alliance successful in replicating effective activity models mostly because committee members are rotated through our 3 cycle per year activity process and faculty obtain examples of successful activity models conducted throughout our alliance. We also provide our participating faculty and governine board members with an annual report describing our outcomes, goals for next year, and brief reports from faculty mentors and students who describe key features that make our activities successful. This reporting structure has led to model replication of curricular activities throughout our region.

\section{Sharing Resources and Best Practices}

Our AMP has generated a wealth of curriculum and research projects which we now propose to innovatively disseminate. For example, through our existing and well-institutionalized summer bridge programs we have developed condensed courses in Calculus, Biology, Physics, Organic Chemistry, and technical English for incoming freshman and community college students who hope to major in mathematics and science-related fields. These courses focus on key material in gate-keeping courses which are required early in their college careers. Through documentation in final project reports, course syllabi, texts, problem sets, and other forms these materials are catalogued and now will be made available to interested faculty through the Internet or by downloading from our computerized data bases. Similarly, our AMP has established an inventory of over 450 undergraduate research projects, results, and final reports for each. Undergraduate research has been conducted and funded through our AMP in virtually every field and subfield of AMP-eligible science. These research reports and results will be made available to interested faculty through our computers so that faculty members can create their own undergraduate research projects for our participating students, in part building upon what has been learned previously and what has worked well for the participating undergraduate students. Similarly, we have now developed an inventory of some $\mathbf{1 , 8 0 0}$ problem sets, primarily in the disciplines of Mathematics (Calculus), Physics, and Chemistry. These problem sets are also be distributed to our participating faculty and student chapters of minority organizations.

\section{Strategic Use of Resources}

WAESO has used high technology to pursue both systemic reform and expansion of its student academic intervention projects beyond the confines of any one campus or region. We have initiated the National Electronic Peer Study Group Network (NEPS), a World Wide Web 
electronic peer group study network that can also be accessed through a toll free phone line via modem. Lower-division students have their peer study groups facilitated by logging onto original problem sets in Calculus, Probability and Statistics, Numerical Methods, Physics, and Chemistry, working their posted problems and sending their questions and/or answers to WAESO upper division students.

As stated before, successful models are replicated through our peer review process. Dissemination is done quickly, since we have three proposal cycles per year, and strategically, since peer faculty become aware of ongoing, successful activities in a particular semester.

Another strategic resource allocation is the use of a regional pool to attract students for summer projects such as our Summer Bridge program for high school or community college transition and Graduate Preparation Institutes that prepare and motivate students for graduate SMET programs. For example, summer bridge programs recruit students from high school and neighboring community colleges who may actually attend college at a different institution within our alliance. This provides students with a broader peer and mentor network than if they were attending the same school in the fall. Graduate Preparation Institutes similarly recruit from within our alliance, thus increasing the motivation factor for students to spend a summer performing research and preparing for the GRE and increasing the pool of mentors that they can draw from for writing letters of recommendation for graduate programs around the country.

\section{Shared Planning And Management}

Our AMP is provided oversight by the Governing Board. The specific activities of our AMP have been carefully determined by its participants through the planning process and budget allocations for each category of activity have been established. At the same time, a level of flexibility has also been provided for. The operational committees have been given genuine authority to establish guidelines for the allocation of funds and to set up a competition among professors across participating institutions in order to award funds on a performance basis. Awards for each of the AMP activities can be refined on a timely basis by the operational committees in order to maximize our effectiveness. Through genuine governance by participating scientists actually engaged in teaching minority students our AMP has made essential mid-course corrections. The allocation of funds through AMP is not a one time award over five years with little possibility for change irrespective of performance. Quite to the contrary, evaluation of each of the participating activities are continuous and annual reports required, so that operational committees have both the freedom and the responsibility to determine their award of funds to the activities that will be supported through NSF AMP funds.

\section{Student Performance}

Over $67 \%$ of our Level 1 (intensively served) students have a cumulative grade point average above 3.0. Moreover, nearly one quarter have cumulative grade point averages above 3.7. This compares very favorably with the national average for the majority population ${ }^{2}$. It is also useful to consider this performance characteristic in light of the fact that $46 \%$ of our students 
involved in Level 1 activities responded that their parents, guardians, and grandparents did not attend college.

One of the key measures that we track in our alliance is the overall retention of African Americans, American Indians, and Hispanics in the transition from freshmen to sophomore at our four year institutions. The table below shows that our overall rate is $77 \%$. Our retention rates for mathematics and chemistry are essentially $100 \%$ while our retention rate in the life sciences is also quite high at $91 \%$.

Table 2. WAESO Retention Data on Four Year Institutions: Freshmen to Sophomore Transition

\begin{tabular}{|l|r|r|r||}
\hline Field & \multicolumn{1}{|c|}{$\begin{array}{c}\text { 1997 } \\
\text { Sophomores }\end{array}$} & $\begin{array}{c}\text { Baseline } \\
\text { Freshmen }\end{array}$ & $\begin{array}{c}\text { Retention } \\
\text { Rate }\end{array}$ \\
\hline Chemistry & 70 & 67 & $104 \%$ \\
\hline Physics/Astronomy & 24 & 32 & $75 \%$ \\
\hline Mathematics & 55 & 53 & $104 \%$ \\
\hline Computer Science & 121 & 146 & $83 \%$ \\
\hline GeoSciences & 27 & 16 & $169 \% \mathbf{1}$ \\
\hline Engineering & 466 & 716 & $65 \%$ \\
\hline Life Sciences & 363 & 398 & $91 \%$ \\
\hline Agricultural Sciences & 59 & 33 & $179 \% \mathbf{1}$ \\
\hline Other SEM & 49 & 146 & $34 \% \mathbf{2}$ \\
\hline Totals & $\mathbf{1 2 3 4}$ & $\mathbf{1 6 0 7}$ & $\mathbf{7 7 \%}$ \\
\hline
\end{tabular}

1 Increase in Sophomores due to undeclared majors and Other SEM students choosing this field as well as the fact that Agricultural Sciences and GeoSciences are lesser known to high school seniors and attract students after their first year.

2 Low retention rate of Other SEM is a natural course of events since students usually declare a more mainstream SMET major after their first year.

\section{Academic Performance Indicator: Enrollment}

At the national level, NACME reports ${ }^{3}$ that freshmen engineering enrollment for underrepresented minorities has again continued a six-year trend of decline by $3.5 \%$. The total decline over this trend has been $10 \%$. However, our alliance is experiencing increased enrollment in SMET majors among African American, American Indian, and Hispanic students in the community colleges and at our four year institutions.

Table 3 shows how the total enrollment of African American, American Indian, and Hispanic SMET students within our alliance's 4 year institutions has grown by about $3.5 \%$ while our total enrollment has grown by $22 \%$. This pattern shows the majority of growth in the SMET enrollment for lower level students in community colleges within our region. 
Table 3. WAESO AMP Total Enrollment (Full and Part Time) Data for Underrepresented Minority Students at Four and Two Year Institutions:

$\begin{array}{lcccc}\text { Ethnicity/ } & \begin{array}{c}\text { Baseline } \\ \text { 4 Year }\end{array} & \begin{array}{c}\text { Baseline } \\ \text { All Institutions }\end{array} & \begin{array}{c}\text { Fall 1996 } \\ \text { 4 Year } \\ \text { Institutions }\end{array} & \begin{array}{c}\text { Fall 1996 } \\ \text { All Institutions }\end{array} \\ \text { African American } & 790 & 1,019 & 819 & 1,171 \\ \text { American Indian } & 792 & 1,440 & 828 & 1,638 \\ \text { Hispanic } & 4,216 & 5,802 & 4,352 & 7,234 \\ \text { Totals } & \mathbf{5 , 7 9 8} & \mathbf{8 , 2 6 1} & \mathbf{5 , 9 9 9} & \mathbf{1 0 , 0 4 3}\end{array}$

\section{Transition to Graduate School}

Historically over $80 \%$ of Project 1000 students are offered admission and $90 \%$ of them are offered significant financial aid in the form of assistantship and fellowships. Project 1000 currently has affiliated with 77 graduate schools representing hundreds of SMET programs that accept applications from our students. Project 1000 will provides extremely valuable services that it has been undertaking since 1988, including the waiving of application fees for student applications at many graduate schools, on site trips to various campuses by ETS staff to help students preparation on the GRE, extensive academic counseling over an 800 telephone number, and highly successful efforts to have all students admitted with the necessary financial aid. In addition, Project 1000 regularly distributes information to qualified students regarding NSF programs such as the NSF graduate programs and the NSF Postdoctoral Research Fellowship Program.

\section{Institutionalization}

Our alliance has experienced a significant effort by faculty and administrators in providing support in terms of cost share and extension of student participation in research projects, Summer Bridge Programs, and Graduate Preparation Institutes. The benefits shown by AMP in terms of enrollment and graduation increases of underrepresented minorities in SMET has helped our universities focus on maintaining our activity models by allocation of resources and raising new funds through capital campaigns.

We have over 500 resource individuals at 75 campuses and organizations participating. Approximately $85 \%$ are scientists, engineers, and other faculty, and $15 \%$ are administrators. Just over $40 \%$ of these resource participants are underrepresented minorities themselves. Our AMP counts on the participation of over 200 research faculty from its comprehensive universities.

Faculty have been augmenting AMP support by adding more underrepresented students in their laboratories through industry sponsorship. Our Summer Bridge and Graduate Preparation programs are providing a significant level of cost-sharing beyond the formal cost sharing reported to NSF each year. These programs also bring in many more tenured faculty since the lead faculty or administrators match up students with mentors, especially in the Graduate Preparation Institutes. 


\section{Student Support Programs}

As the result of the extensive analysis that the WAESO conducted of its own programs and resources, we have 147 participating programs at our alliance institutions at the undergraduate college level. Many of these programs are already institutionalized and do not require additional resources, but rather, more students. WAESO makes a strong commitment to each participating student at the undergraduate level. Moreover we understand more detailed information (such as for example that $46 \%$ are first generation college attendees) about our students that help us develop intervention strategies. Individualized faculty mentoring has been a cornerstone of our activities that enable us to quickly respond to the needs of the students. Our activities are planned and conducted three times a year. This provides a unique level of flexibility to serve students and provide mentors with the resources to ensure that students excel academically.

Limited only by the interest of the participating students themselves or the simple lack of human or financial resources, each student has access to the core activities and programs that follow:

\section{LEVEL 1 (INTENSIVE) ACTIVITIES}

\section{Summer Bridge Program:}

Designed for incoming freshmen during the summer prior to the student's freshman year, bridge programs feature academic work in areas that assist students' success in courses such as Calculus, Biology, Physics, Inorganic/Organic Chemistry, and technical English: courses that students hoping to major in math and science-related fields are required to pass early in their college careers. The programs also feature college survival skills presentations, motivational speakers, and foster the development of peer study/peer networking groups.

\section{Peer Study Groups:}

On-Site Peer Study Groups. (for incoming freshman in their summer prior to matriculation, community college, or four-year college students). Each of these groups involves at least five underrepresented minority undergraduate students as well as majority students. Students study under a mathematics, engineering, or science instructor for undergraduate "gatekeeping" courses such as calculus, physics, and chemistry. Peer study groups work at a more advanced level than the courses associated with the group so that students can excel academically.

The National Electronic Peer Group Study Network (NEPS). This program serves the same students and has the same goals, objectives, and content as the On-Site Peer Study Groups (see immediately above), except that NEPS mobilizes advanced minority students and their faculty supervisors to aid lower-division students through a technologically advanced and sophisticated delivery system providing interaction through modem and/or the Internet. Through the electronic medium students who are separated by distance in Chemistry, Physics, Calculus, and other disciplines work cooperatively with faculty and each other. NEPS will serve students both within WAESO, and potentially, the entire nation. 
Undergraduate Summer Research and Graduate Preparation Institute:

Designed for students between their sophomore and junior years or between their junior and senior years, these summer institutes feature academic programs in research methodology, experimental design, mathematics or statistics, and related topics, customized to the students' needs and academic fields of interest. Besides academic preparation, students will receive orientation to the Graduate Record Exam (GRE) as well as guidance and counseling concerning preparing for and applying to graduate programs.

Faculty-Directed Individual and Group Undergraduate Student Research Projects:

The goal of this program is to provide students with "hands on" opportunities to serve as apprentice researchers to a faculty member's research project which genuinely prepares them for further research at the graduate level. These projects have academic expectations for the participating underrepresented minority students above and beyond the ordinary expectations of their course work.

\section{LEVEL 2 (NON-INTENSIVE) ACTIVITIES}

\section{Skill Building Workshops:}

Workshops are designed to increase student performance on the graduate record examination. These workshops sessions are a one-day experience providing guidance and orientation to help reduce the fudge variables unrelated to student aptitudes for graduate study that underrepresented ethnic minority students have encountered in the GRE and other standardized tests as documented by current research.

\section{Information Presentation:}

Building upon the past successes of Project 1000, we help our students beginning with their sophomore year and/or transition from community college to four-year college with computerized and printed: (a) information about graduate school and various graduate programs within our geographic service area and nationally; (b) information that will help our students to cope with the admissions process into graduate school; (c) computerized and printed guidance, counseling and simulations to help them cope with the GRE; (d) information and counseling that addresses and combats the major myths and misassumptions about both graduate studies and graduate admissions that students harbor; and (e) a state-of-the art computer aided admissions application form that will permit students to apply simultaneously to numerous graduate programs around the nation with much greater ease and efficiency than is currently possible. Our WAESO students are able to effectively submit electronically most of their application forms as well as many other required and supplementary graduate materials that are currently typed or written on paper and submitted in hard copy. Thus, our students are able to much more easily submit multiple applications to graduate school with the result that a much higher percentage of students will receive admissions with financial aid. 


\section{Use of Technology}

Technology is being used in several different, cost-effective ways. Through our World Wide Web sites we provide students with financial aid and academic program information. Through NEPS we have developed peer study groups over the Internet providing cost-effective methods for increasing academic achievement of our students and developing peer mentoring across institutions since upper division students communicate with lower division students who work on the problem sets posted on the World Wide Web. We also support computerized applications for graduate programs providing students with a wealth of information about hundreds of graduate programs around the U.S. as well as permitting them to electronically apply in principle to as many as 40 graduate schools through an electronic format that features computerized facsimiles of graduate application forms and graduate programs at institutions around the nation.

Faculty are also benefiting from our strategic infusion of technology in our alliance. Reports and project descriptions of our Phase I and Phase II activities are made available in electronic or printed form giving them successful models and the student achievement outcomes that were realized in these activities. This is a valuable resource made available by our alliance through electronic applications for students and reports as well as the development of computer databases from scanned reports for our earlier Phase I activities.

\section{High School and Community College Outreach}

At the pre-collegiate level, a total of 10,066 7th through 12th grade students were served through Project PRIME (Project to Improve Minority Education) and the Navajo Higher Education Demonstration Model. Our pre-college programs are achievement oriented, focusing on preparing minority and majority students for undergraduate majors in science and engineering fields. In addition, our summer bridge programs aid incoming freshman during the summer prior to their matriculation and which features academic work in such courses as Calculus, Biology, Physics, Inorganic/Organic Chemistry, and technical English, as well as college survival skills, motivational speakers, and the development of peer study/peer networking groups. The precollegiate programs have already been operating for seven years and are helping to bring thousands of additional minority students into higher education, many of them in science and engineering. For example, in Arizona we have changed the educational profile of minority students in the participating schools. One index of this higher level of achievement is the number of Arizona Advanced Placement tests in math and science which rose radically between 1987 (our baseline year) and 1994, both generally, and among minority students. In 1987, 2,266 students took the AP exam in Arizona. By 1991, that number had increased to 5,647, a full 149\% increase. Among underrepresented minority students, in 1987 only 206 students took the Arizona AP examinations in mathematics and sciences. In 1991, 900 took the exams, a full $337 \%$ increase.

\section{The Community College Pool}

The community college pool of African Americans, American Indians, and Hispanics who 
have declared SMET majors are shown in the table below. Sizable percentage increases are being realized from the baseline year: African Americans increased by 54\%; American Indians increased by $25 \%$; and Hispanics increased by $82 \%$. Our community colleges are important to our alliance for developing a pool of students for the baccalaureate SMET pipeline.

Table 4. WAESO AMP Total Enrollment (Full and Part Time) Data for Underrepresented Minority Students at Community Colleges:

$\begin{array}{lcc}\text { Ethnicity/Race } & \begin{array}{c}\text { Baseline } \\ \text { Community } \\ \text { Colleges }\end{array} & \begin{array}{c}\text { Fall 1996 } \\ \text { Community } \\ \text { Colleges }\end{array} \\ \text { African American } & 229 & 352 \\ \text { American Indian } & 648 & 810 \\ \text { Hispanic } & 1,586 & 2,882 \\ \text { Totals } & \mathbf{2 , 4 6 3} & \mathbf{4 , 0 4 4}\end{array}$

In Arizona, Colorado, New Mexico, and Utah a significant number of our SMET underrepresented minority students transfer from community colleges to four-year institutions within our region. However, our community college students also transfer to four-year institutions outside of our region. Tracking enrollment data of minority students at 6 of our fouryear institutions which comprise $57 \%$ of our underrepresented minority students enrollment, about $24 \%$ of these students transferred from community colleges. Community college transfer students have been shown to do as well as non-transfer students, and they graduate with higher cumulative grade point averages. In our alliance, about $33 \%$ of our SMET community college students transfer to four-year institutions within two years of being at the first institution. This is higher than the national rate of transfers from community colleges to four-year institutions of $22 \%^{4}$.

Our community college students are highly motivated to pursue baccalaureate and advanced degrees. When asked about the final SEM degree level that they are pursuing, 95\% of our Level 1 community college students responded that they are seeking B.S. or higher degrees. This is significantly higher than a national study ${ }^{4}$ which reported that $25 \%$ of community college students indicated that they are working towards a bachelor's degree. It is even more striking that $59 \%$ of our Level 1 students responded that they are working towards M.S. or Ph.D. degrees.

\section{Summary}

WAESO has made use of and built upon our documentably successful programs, many of which already been underway for several years, but which now have been systematically correlated with each other into a grand initiative that is far more effective than the sum of its parts. We have built upon our programs in Arizona, Colorado, New Mexico, Nevada, Western Texas and Utah, incorporating numerous successful initiatives that have received NSF funding, that are part of government laboratories such as Los Alamos and Sandia National Laboratories or 
that are funded by foundations, state legislatures, and each institution's own dollars. Through the coordinative efforts of WAESO, these programs now work to maximize their programmatic effectiveness within an overall, concerted structure with regional goals on behalf of underrepresented minority students.

In this genuine alliance of scientists, administrators, university and college educators, representatives of government laboratories and agencies, corporations, professional organizations, and others, the programs share information across institutions and across state lines and coordinate their operations so that students progress from one program and one institution to another in an orderly fashion as they advance along the academic pipeline. Similarly, each program participates in the WAESO tracking and evaluation system.

WAESO benefits from the enormous success of our previous 5-year Phase I project, the Southern Rocky Mountain Alliance for Minority Participation (SRM-AMP). The SRM-AMP, successful in its highly challenging goal of doubling the number of underrepresented minority science, engineering, mathematics baccalaureates, has had a major impact on the campus environments of our participating institutions. Professors and other educators are all enthusiastic in participating in WAESO which is acknowledged as an effective educational leader and these educators are now working in an environment with significantly more successful underrepresented students than five years ago. Scientists, specifically faculty members working with students, have been involved in every aspect of the project and have primary control over the project and the allocation of funds, through their participation in the operational committees. In contrast to years past, before our NSF grant, where scientists were wary of such programs, we have a situation that is notable for the enthusiasm of our participating faculty members who recognize the proven, documented success of WAESO and its predecessor, SRM-AMP, who have participated in the great success of the students they are mentoring, and who look forward to further building upon those successes.

WAESO is well on its way to institutionalizing an extraordinary and unprecedented level of cooperation among and within the participating institutions. This cooperative structure will become a permanent one. Long after the NSF funding cycle phases out, the overall structure will continue to exist and work to meet the challenge of educating and graduating more minority bachelor's and doctorates. We have been able to put in place both the design and the accompanying operational mechanisms to coordinate a regional, coherent, sequential and systematic approach to the challenge of educating minorities in science and engineering through the Ph.D. The WAESO institutions genuinely operate within a framework of a sophisticated consortial structure that takes the best and most effective programs from each campus and brings them together into a unified strategy to meet the problem. There is now a common set of goals, purpose, and overall programmatic approach to guide the 36 participating campuses and organizations and over 200 participating programs.

We have brought together educational institutions including secondary schools, community colleges, four-year colleges, and universities, both public and private. The Alliance counts on the participation of a wide range of organizations both in the region and nationally, including corporations, government laboratories, the College Board, the Educational Testing Service, and 
many others. WAESO has been designed to make use of NSF funds to expand activities that have already proved successful and have often received the recognition of national foundations and professional organizations. We also have the participation of professional organizations, government laboratories and agencies, and 21 major corporations that serve the Rocky Mountain South region. These include the Los Alamos National Laboratory, Motorola, Inc., IBM, Shell Development, McDonnell Douglas, Du Pont, Phelps Stokes Fund, Sandia National Laboratory, Western Interstate Commission for Higher Education, and many others.

WAESO provides a mechanism for all of the participating programs to coordinate their fundraising, the tracking and monitoring of their students, and the evaluation of their activities. Finally, the participating institutions are being permanently and positively changed by virtue of the substantial increase that they are experiencing in their minority student populations. WAESO and its predecessor, SRM-AMP have brought minority students into colleges and graduates schools at a rate never experienced before.

\section{Bibliography}

1. Science and Engineering Degrees, by Race/Ethnicity of Recipients, NSF 97-xxx, forthcoming publication, http://www.nsf.gov/cgi-bin/getpub?nsf96329).

2. A Descriptive Summary of 1992-1993 Bachelor's Degree Recipients One Year Later, August 1996, NCES 96-158)

3. AIChE Extra, October 1997, page 8.

4. NCES 97-266

\section{Biographies}

ANTONIO A. GARCÍA Dr. Antonio A. García is an associate professor with joint appointments in the Chemical and Bio Engineering programs at Arizona State University. He is an active researcher in biochemical engineering while directing WAESO and co-directing INVSEE which is making available for the first time interactive, remote operation of scanning probe microscopes over the World Wide Web.

GARY D. KELLER Dr. Gary D. Keller is a Regents' Professor at Arizona State University and interim Director of the Hispanic Research Center. In 1993 the Charles A. Dana Foundation awarded Dr. Gary D. Keller, a \$50,000 dollar prize (which he donated to his minority projects) for "Pioneering Achievements in Education".

ALBERT L. MCHENRY Dr. Albert L. McHenry is the Dean of the School of Technology at Arizona State University, virtually the only African American nationwide to direct an engineering technology school at a major research university. Dr. McHenry received the Frederick J. Berger award by ASEE for "major contributions to the advancement of engineering technology education".

FRED BEGAY Dr. Fred Begay is responsible for creating and coordinating math and science education programs at Los Alamos National Laboratory. Dr. Fred Begay (the first Navajo to have earned a Ph.D. in physics in the U.S.) 
received the NSF's Lifetime Achievement Award in 1994 for making stellar efforts in nuclear fusion and substantive contributions to minority students. 